\title{
GC/MS chemical analysis of lavandin (Lavandula $x$ intermedia) hydrolat: successive extraction fractions
}

\author{
Dejan PljeVljakušić ${ }^{*}$ And Zorica Drinić ${ }^{1}$ \\ ${ }^{1}$ Institute for Medicinal Plants Research "Dr. Josif Pančić", Tadeuša Košćuška 1, 11000 Belgrade, Serbia \\ *Corresponding author:dpljevljakusic@mocbilja.rs
}

Received: September 10, 2020

Accepted: November 18, 2020

Published on-line: December 19, 2020

Published: December 25, 2020

\begin{abstract}
Hydrolats are valuable co-products of the essential oil distillation process, whose volatile compounds can be quantified by various methods. In this paper, we have tried to estimate the liquid-liquid extraction cycle number threshold for volatile compounds quantification of lavandin (Lavandula $x$ intermedia) hydrolat. For this purpose, ten consecutive hydrolat extractions with $n$-hexane were analyzed GC/MS with hexadecane (C16) as an internal standard and compared with the lavandin essential oil. The chemical composition of the lavandin hydrolat showed similarity with its essential oil to the great extent, while volatile compounds dissolved in hydrolat exclusively belonged to the class of oxygenated monoterpenes. The total amount of extracted compounds has been estimated to $2174.2 \mathrm{mg} / \mathrm{L}$, where the most dominant compounds in lavandin hydrolat were cis- and trans-furanoid linalool oxide (676.3 and $634.1 \mathrm{mg} / \mathrm{L}$, respectively), followed by much smaller amounts of linalool, camphor, and 1,8-cineole (167.6, 157.0, and $148.2 \mathrm{mg} / \mathrm{L}$, respectively). Cumulative recoveries of total compounds yield after the third, fifth, and eighth extractions were $88 \%, 96 \%$, and $99 \%$, respectively. Combined fraction analysis confirmed that in the first 5 cycles more than $95 \%$ of the total yield (from $10 \mathrm{cy}-$ cles) of extracted volatile compounds can be collected. Based on the results of this study, for volatile compounds quantification in lavandin hydrolat, 5 cycles of $n$-hexane liquid-liquid extraction can be recommended.
\end{abstract}

Key words: hydrosol, essential oil, volatile compounds, solubility, hydrolat, gas chromatography

http://dx.doi.org/10.5937/leksir2040033P

\section{INTRODUCTION}

Hydrolats are valuable co-products obtained from aromatic and other plants by steam distillation. During this process, some components of the essential oil are dissolved in water in a certain ratio. Beside hydrolat, there are many different names for this co-product among which hydrosol, aromatic water, floral water, essential water, and herbal distillates are the most common. Hydrolats have many industrial applications such as cosmetics, perfumery, pesticides, aromatherapy, pharmaceutical, medical, and religious (Rajeswara Rao, 2013). Since some essential oils have a relatively high proportion of water-soluble compounds, a significant amount of the essential oil could retain in the water during the distillation process. Therefore, hydrolats of excellent quality are obtained when cohobation is an integral part of the distilling process (Price and Price, 2004). Essential oil components are lipophilic and have different solubility in water at room temperature, mostly below $2 \%$ (Chen et al., 2014). However, due to different water-solubility of the components, the chemical analysis of the hydrolate will show a different profile compared to the essential oil from which it originates (Catty, 2001). The quality of the hydrolate may also depend on the collection time so that the early collected contain more low boiling point and the later collected more terpenoids with higher boiling points. (Rajeswara Rao, 2013). Some research indicates that for the therapeutic value of hydrolates, separation of fractions is more desirable than the entire distillation water collected at the end of the distillation process (Rose, 1999).

Lavandin (Lavandula $\times$ intermedia) is an artificially created hybrid of true lavender (Lavandula augustifolia) and spike lavender (Lavandula latifolia), which is widely cultivated due to its desirable characteristics such as oil yield and cultivation benefits (Lesage-Meessen et al., 2015; Lis-Balchin, 2002; Tucker et al., 1984).

Considering that it is generally accepted that less than $2 \%$ of essential oil is dissolved in hydrolats and that there is a lack of methods for quantification of individual components in the literature, the aim of this paper was to test the method of hydrolat compounds quantification using an internal standard on the example of lavandin distillation. In order to evaluate the yield of total and individual extracted volatile compounds dissolved in the hydrolate, individual and combined $n$-hexane 
liquid-liquid extractions were analyzed.

\section{MATERIALS AND METHODS}

\subsection{Standards and reagents}

Sodium sulfate anhydrous $\left(\mathrm{Na}_{2} \mathrm{SO}_{4}\right)$ and hexadecane were purchased from Sigma Chemicals Co. (USA), while $n$-hexane and distilled water were purchased from Zorka Pharma, Šabac (Serbia). All chemicals used in the experimental procedure were of analytical grade purity.

\subsection{Plant material}

Flowers of lavandin (Lavandula $\times$ intermedia) were purchased from the Production sector of the Institute for Medicinal Plant Research "Dr. Josif Pančić", Belgrade.

\subsection{Essential oil and hydrolat extraction procedures}

Isolation of essential oil and hydrolat was performed using the hydro-distillation method using a Clevenger type apparatus according to the procedure I of the Ph. Jug. IV (1984). Lavandin flowers $(40 \mathrm{~g})$ were placed in flat-bottom flask $(1 \mathrm{~L})$ and filled with tap water until mass of $493 \mathrm{~g}$. After setting the Clevenger apparatus on the heating body, an additional $7 \mathrm{~mL}$ of water was introduced into the system through a pipe above the burette, making a total mass of water of approximately 460 $\mathrm{g}$, and together with the sample $500 \mathrm{~g}$. Hydrolat was collected from the burette after the distillation process. The essential oil was collected and dried over anhydrous sodium sulfate. The essential oil yield, expressed as a percentage, was calculated on a moisture-free basis.

\subsection{Sample preparation}

Oil samples $(20 \mu \mathrm{L})$ were dissolved in $n$-hexane $(2 \mathrm{~mL})$ and stored at $4{ }^{\circ} \mathrm{C}$ until further analysis. Hydrolat was extracted with $n$-hexane. For optimization of the number of extraction cycles liquid-liquid extraction (LLE) of volatile compounds dissolved in water was performed ten times $(5 \mathrm{~mL}$ of hydrosol with $10 \times 1 \mathrm{~mL} n$-hexane). Hexadecane (C16) was used as an internal standard for quantification of volatile compounds dissolved in hydrolat. For this purpose, an internal standard stock solution has been made ( $5.5 \mathrm{mg}$ in $1 \mathrm{~mL} n$-hexane). In each extraction party, $100 \mu \mathrm{L}$ of internal standard has been added so that the final concentration of internal standard was $500 \mathrm{mg} / \mathrm{L}$. All samples were stored in the freezer until further analysis.

In order to validate the yield ratio of the extracted compounds from the lavandin hydrolat, the first five (1-5) and the last five (6-10) LLE fractions were combined into separate groups. Extractions were performed on newly prepared hydrolat from the same plant material and by the same procedure as for the analysis of individual fractions. In $1 \mathrm{~mL}$ of combined hexane fractions, $100 \mu \mathrm{L}$ of the internal standard has been added so that the final concentration of internal standard was $500 \mathrm{mg} / \mathrm{L}$. Samples were stored in the freezer until further analysis. Chemical analysis of combined fractions was performed under the same GC/MS conditions, as for analysis of individual fractions.

\subsection{Chemical analysis}

The chemical composition of the essential oil and hydrolat extraction parties was analyzed using GC/MS technique. GC/MS analyses were performed on a Shimadzu GCMSQP2010 ultra mass spectrometer fitted with a flame ionic detector and coupled with a GC2010 gas chromatograph. The InertCap5 capillary column $(60.0 \mathrm{~m} \times 0.25 \mathrm{~mm} \times 0.25 \mu \mathrm{m})$ was used for separation. Helium (He), at a split ratio of 1:5 and a linear velocity of $35.2 \mathrm{~cm} / \mathrm{s}$ was used as a carrier gas. Initially, the oven temperature was $60^{\circ} \mathrm{C}$, which was held for $4 \mathrm{~min}$, then increased to $280{ }^{\circ} \mathrm{C}$ at a rate of $4{ }^{\circ} \mathrm{C} / \mathrm{min}$, and held for $10 \mathrm{~min}$. The injector and detector temperatures were $250^{\circ} \mathrm{C}$ and $300^{\circ} \mathrm{C}$, respectively. The ion source temperature was 200 ${ }^{\circ} \mathrm{C}$. The identification of the constituents was performed by comparing their mass spectra and retention indices (RIs) with those obtained from authentic samples and/or listed in the NIST/Wiley mass-spectra libraries, using different types of search (PBM/NIST / AMDIS) and available literature data (Adams, 2007).

\section{RESULTS AND DISCUSSION}

\subsection{Essential oil chemical composition}

The yield of the essential oil was $6.2 \%$, which corresponds to the lower values of the previously published data on oil yields of lavandin (Arabaci et al., 2007; Kara and Baydar, 2013; Pistelli et al., 2017; Renaud et al., 2001). Chromatographic analysis of the essential oil showed a typical lavandin profile, where among 57 integrated peaks 46 were identified, representing $98.7 \%$ of total compounds (Table 1). The most abundant compounds were oxygenated monoterpenes (91.2\%) such as linalool (23.1\%), camphor (16.3\%), 1,8-cineole (14.5\%), linalool acetate $(10.0 \%)$, borneol (5.2\%) and caryophyllene oxide $(2.1 \%)$. Similar oil patterns have been reported in previously published papers (Bajalan et al., 2017; Blažeković et al., 2018; Carrasco et al., 2016; Garzoli et al., 2020). Sesquiterpenes and their oxygenated forms are much less abundant in the essential oil than oxygenated monoterpenes with total values of $0.7 \%$ and $3.3 \%$, respectively.

\subsection{Hydrolat chemical composition}

The chemical composition of the lavandin hydrolat is generally similar to the main components of the essential oil (Table 2). In our experiment, no sesquiterpene component was detected in the aqueous solution. The volatile compounds dissolved in water exclusively belonged to the class of oxygenated monoterpenes, which is mostly similar to previously published analyzes (Baydar and Kineci, 2009; Politi et al., 2020; Śmigielski et al., 2013). The most abundant compounds in lavandin hydrolat were cis- and trans-furanoid linalool oxide $(676.3$ and $634.1 \mathrm{mg} / \mathrm{L}$, respectively), followed by much smaller amounts of linalool, camphor, and 1,8-cineole (167.6, 157.0 , and $148.2 \mathrm{mg} / \mathrm{L}$, respectively). The next compounds regarding quantity were cis-pyranoid linalool oxide, which co-eluted together with borneol at the same retention time, hotrienol, $\alpha$-terpineol, and trans-pyranoid linalool oxide (89.7, $79.7,67.0$, and $63.4 \mathrm{mg} / \mathrm{L}$, respectively). Two furanoid linalool oxide isomers, which amount in essential oil fluctuated about $4 \%$ each, were expressed in hydrolat in the highest amounts among all water-soluble compounds. Tannous et al. (2004) reported that oxygenated compounds are more water-soluble. So, further oxidation of the monoterpene alcohols, cis- and trans-linalool to the corresponding oxides, probably leads to their better solubility in water, which is why they are the compounds with the highest share. The higher amount of cis- and trans-linalool oxide in lavandin hydrolat than in essential oil was reported by Śmigielski et al. (2013). Baydar and Kineci (2009) reported the much higher content of linalool oxide in hydrolat than in essential oil, also. Furthermore, two pyranoid linalool oxides, which were not observed in the essential oil, were detected in hydrolat in significant amounts. Also, in the essential oil, co-elution of cis-pyranoid linalool oxide with borneol was not detected. This indicates that the total amounts of these pyranoid linalool oxide isomers from the plant material are dissolved in the hydrolat. Our results of lavandin hydrolat chemical composition are not in accordance with the majority of previously published reports, where linalool was the most abundant compound (42-56 \%), followed by cam- 
Table 1. Chemical profile of lavandin (Lavandula $\times$ intermedia) essential oil

\begin{tabular}{|c|c|c|c|}
\hline \# & Compound $^{\mathrm{a}}$ & $\mathrm{RI}^{\mathrm{b}}$ & $\% \mathrm{~m} / \mathrm{m}$ \\
\hline 1 & $\alpha$-pinene & 931.5 & 0.26 \\
\hline 2 & camphene & 948.5 & 0.56 \\
\hline 3 & 1-octen-3-ol & 974.4 & 0.26 \\
\hline 4 & $\beta$-pinene & 978.5 & 0.32 \\
\hline 5 & 3-octanone & 981.3 & 0.19 \\
\hline 6 & myrcene & 987.4 & 0.45 \\
\hline 7 & dehydro-1,8-cineole & 990.0 & 0.18 \\
\hline 8 & hexyl acetate & 1004.8 & 0.30 \\
\hline 9 & pinocarvone & 1009.5 & 0.15 \\
\hline 10 & $p$-cymene & 1019.7 & 0.14 \\
\hline 11 & limonene & 1025.0 & 0.37 \\
\hline 12 & 1,8-cineole & 1029.1 & 14.55 \\
\hline 13 & trans- $\beta$-ocimene & 1039.3 & 0.43 \\
\hline 14 & $\gamma$-terpinene & 1052.6 & 0.12 \\
\hline 15 & cis-sabinene hydrate & 1062.6 & 0.20 \\
\hline 16 & cis-furanoid linalool oxide & 1067.7 & 4.09 \\
\hline 17 & trans-furanoid linalool oxide & 1083.4 & 3.64 \\
\hline 18 & linalool & 1096.1 & 23.07 \\
\hline 19 & hotrienol & 1099.0 & 1.51 \\
\hline 20 & n.i. & 1124.2 & 0.09 \\
\hline 21 & n.i. & 1137.6 & 0.36 \\
\hline 22 & camphor & 1147.1 & 16.29 \\
\hline 23 & lavandulol & 1159.8 & 0.90 \\
\hline 24 & borneol & 1166.7 & 5.23 \\
\hline 25 & terpinen-4-ol & 1176.6 & 0.72 \\
\hline 26 & $p$-cymen-8-ol & 1182.0 & 0.89 \\
\hline 27 & $\alpha$-terpineol & 1191.0 & 3.05 \\
\hline 28 & myrtenol & 1197.8 & 0.24 \\
\hline 29 & n.i. & 1202.1 & 0.28 \\
\hline 30 & verbenone & 1211.8 & 0.14 \\
\hline 31 & trans-carveol & 1219.0 & 0.17 \\
\hline 32 & nerol & 1225.2 & 0.47 \\
\hline 33 & isobornyl formate & 1232.2 & 0.37 \\
\hline 34 & carvone & 1246.5 & 0.15 \\
\hline 35 & linalool acetate & 1253.1 & 9.97 \\
\hline 36 & lavandulyl acetate & 1286.4 & 2.61 \\
\hline 37 & bornyl acetate & 1289.7 & 0.19 \\
\hline 38 & hexyl tiglate & 1315.9 & 0.21 \\
\hline 39 & n.i. & 1324.4 & 0.09 \\
\hline 40 & verbanol acetate & 1336.5 & 0.38 \\
\hline 41 & neryl acetate & 1347.2 & 0.64 \\
\hline 42 & geranyl acetate & 1364.7 & 1.33 \\
\hline 43 & $\alpha$-santalene & 1409.9 & 0.18 \\
\hline 44 & trans-caryophyllene & 1416.2 & 0.39 \\
\hline 45 & cis- $\beta$-farnesene & 1438.6 & 0.11 \\
\hline 46 & lavandulyl isovalerate & 1495.7 & 0.26 \\
\hline 47 & n.i. & 1516.9 & 0.24 \\
\hline 48 & n.i. & 1553.9 & 0.12 \\
\hline 49 & spathulenol & 1575.9 & 0.16 \\
\hline 50 & caryophyllene oxide & 1582.3 & 2.10 \\
\hline 51 & epi- $\alpha$-cadinol & 1638.2 & 0.50 \\
\hline 52 & n.i. & 1659.9 & 0.10 \\
\hline \multirow[t]{7}{*}{53} & 14-hydroxy-9-epi-trans-caryophyllene & 1672.3 & 0.25 \\
\hline & SUM od identified compounds & & 98.72 \\
\hline & Monoterpenes & & 2.85 \\
\hline & Oxigenated monoterpenes & & 91.25 \\
\hline & Sesquiterpenes & & 0.68 \\
\hline & Oxigenated sesquiterpenes & & 3.27 \\
\hline & Other & & 1.94 \\
\hline
\end{tabular}

${ }^{a}$ n.i. - stands for not identified compounds

${ }^{b} \mathrm{RI}$ - retention index relative to $\mathrm{C}_{8}-\mathrm{C}_{40} n$-alkanes on InertCap5 column phor (13-24\%) and 1,8-cineole (8-24\%), while linalool oxide isomers were detected in smaller amounts (3-6\%) (Baydar and Kineci, 2009; Politi et al., 2020; Yohalem and Passey, 2011). Some other sources reported components such as 1,8-cineole and camphor as the most dominant in lavandin hydrolat (53 and $67 \%$, respectively) (Garzoli et al., 2020; Jeon et al., 2013). Reports dealing with the chemical composition of true lavender (L. angustifolia) hydrolats also indicate a high content of linalool (26-52 \%)(Kaloustian et al., 2008; Prusinowska et al., 2016; Śmigielski et al., 2013). However, none of the previously published reports list linalool oxides as the dominant compounds in the hydrolat, while pyranoid types of linalool oxides were not even mentioned. These differences can arise as a consequence of different starting plant material, as well as different distillation techniques. Kunicka-Styczyńska et al. (2015) reported different chemical composition of true lavender hydrolats depending on whether fresh or dried flowers were distilled. No linalool oxides were detected in the fresh flower hydrolat, while in the case of dried flowers they were detected in a significant amount (3-10\%). The distribution of the components dissolved in the hydrolat largely depends on the presence of that component in the oil, but also on the water-solubility of that component. Yalkowsky et al. (2016) reported different water-solubilities for 1,8-cineol (3.1-3.4 g/L), linalool (1.5-1.8 g/L), camphor (1.5-2.0 g/L), and borneol (0.7 $\mathrm{g} / \mathrm{L})$ at $25^{\circ} \mathrm{C}$.

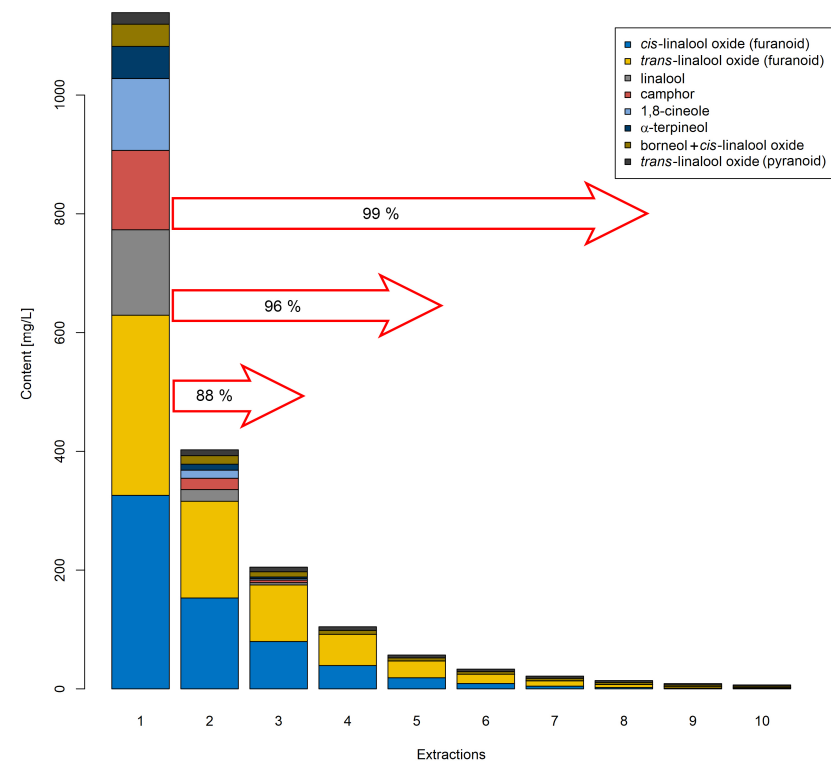

Fig. 1. Content of eight most abundant lavandin (Lavandula $\times$ intermedia) hydrolat compounds in ten consecutive extractions.

\subsection{Fractions}

In ten consecutive LLE of lavandin hydrolat about $2 \mathrm{~g} / \mathrm{L}$ of dissolved oxygenated monoterpene compounds have been quantified (Table 2). This amount of dissolved essential oil in water is in the accordance with previously published reports that dissolved compounds contents were in range from less than $1 \mathrm{~g} / \mathrm{L}$ (Labadie et al., 2015) to about $3.5 \mathrm{~g} / \mathrm{L}$ (Martínez-Gil et al., 2013). 
Table 2. Content of dissolved essential oil compounds in ten consecutive liquid-liquid lavandin (Lavandula $\times$ intermedia) hydrolat extractions

\begin{tabular}{|c|c|c|c|c|c|c|c|c|c|c|c|c|c|c|c|c|c|}
\hline \multirow[b]{3}{*}{ \# } & \multirow[b]{3}{*}{ Compound $^{\mathrm{a}}$} & \multirow[b]{3}{*}{$\mathrm{RI}^{\mathrm{b}}$} & \multicolumn{10}{|c|}{ Extractions } & \multirow[b]{2}{*}{ SUM } & \multirow[b]{2}{*}{ SUM } & \multicolumn{3}{|c|}{ Validation } \\
\hline & & & 1 & 2 & 3 & 4 & 5 & 6 & 7 & 8 & 9 & 10 & & & $1-5$ & $6-10$ & SUM \\
\hline & & & $\mathrm{mg} / \mathrm{L}$ & $\mathrm{mg} / \mathrm{L}$ & $\mathrm{mg} / \mathrm{L}$ & $\mathrm{mg} / \mathrm{L}$ & $\mathrm{mg} / \mathrm{L}$ & $\mathrm{mg} / \mathrm{L}$ & $\mathrm{mg} / \mathrm{L}$ & $\mathrm{mg} / \mathrm{L}$ & $\mathrm{mg} / \mathrm{L}$ & $\mathrm{mg} / \mathrm{L}$ & $\mathrm{mg} / \mathrm{L}$ & $\% \mathrm{~m} / \mathrm{m}$ & $\mathrm{mg} / \mathrm{L}$ & $\mathrm{mg} / \mathrm{L}$ & $\mathrm{mg} / \mathrm{L}$ \\
\hline 1 & 1,8-cineole & 1029.2 & 121.0 & 13.6 & 2.4 & 2.1 & 1.9 & 1.7 & 1.6 & 1.5 & 1.2 & 1.2 & 148.2 & 6.8 & 104.4 & - & 104.4 \\
\hline 3 & cis-linalool oxide (furanoid) & 1071.8 & 325.9 & 153.1 & 79.7 & 39.3 & 18.7 & 9.0 & 4.6 & 2.3 & 1.1 & 0.6 & 634.3 & 29.2 & 705.3 & 28.13 & 733.4 \\
\hline 4 & trans-linalool oxide (furanoid) & 1087.9 & 303.3 & 162.8 & 95.2 & 52.6 & 33.4 & 11.6 & 8.1 & 5 & 2.6 & 1.6 & 676.2 & 31.1 & 755.2 & 44.01 & 799.2 \\
\hline 5 & linalool & 1096.0 & 143.9 & 19.7 & 4.0 & - & - & - & - & - & - & - & 167.6 & 7.7 & 106.3 & - & 106.3 \\
\hline 6 & hotrienol & 1100.4 & 63.4 & 12.8 & 3.4 & - & - & - & - & - & - & - & 79.6 & 3.7 & 98.0 & - & 98.0 \\
\hline 7 & lilac aldehyde B & 1138.4 & 9.3 & 2.0 & - & - & - & - & - & - & - & - & 11.3 & 0.5 & 12.3 & - & 12.3 \\
\hline 9 & sabina ketone & 1155.5 & 1.8 & - & - & - & - & - & - & - & - & - & 1.8 & 0.1 & - & - & - \\
\hline 10 & lavandulol & 1160.7 & 7.9 & 1.6 & - & - & - & - & - & - & - & - & 9.5 & 0.4 & 8.8 & - & 8.8 \\
\hline 11 & cis-linalool oxide (pyranoid) + borneol & 1167.0 & 37.4 & 14.4 & 8.9 & 6.6 & 5.1 & 4.5 & 4.1 & 3.5 & 2.8 & 2.4 & 89.7 & 4.1 & 70.6 & 14.75 & 85.4 \\
\hline 12 & trans-linalool oxide (pyranoid) & 1169.7 & 19.5 & 9.8 & 7.7 & 6.1 & 4.8 & 4.1 & 3.7 & 3.1 & 2.4 & 2.0 & 63.2 & 2.9 & 45.2 & 17.98 & 63.2 \\
\hline 13 & terpinen-4-ol & 1177.5 & 7.9 & 1.5 & - & - & - & - & - & - & - & - & 9.4 & 0.4 & 8.6 & - & 8.6 \\
\hline 14 & p-cymen-8-ol & 1183.7 & 10.3 & 2.4 & - & - & - & - & - & - & - & - & 12.7 & 0.6 & 10.7 & - & 10.7 \\
\hline 15 & $\alpha$-terpineol & 1192.2 & 54.1 & 1.0 & 2.8 & - & - & - & - & - & - & - & 57.9 & 2.7 & 40.1 & - & 40.1 \\
\hline 16 & myrtenol & 1198.6 & 2.5 & 2.9 & 1.5 & - & - & - & - & - & - & - & 6.9 & 0.3 & 3.7 & - & 3.7 \\
\hline 17 & cis-4-caranone & 1202.8 & 2.9 & - & - & - & - & - & - & - & - & - & 2.9 & 0.1 & 2.1 & - & 2.1 \\
\hline 18 & verbenone & 1213.0 & 5.4 & 1.8 & - & - & - & - & - & - & - & - & 7.2 & 0.3 & 8.8 & - & 8.8 \\
\hline 19 & trans-carveol & 1220.1 & 2.8 & - & - & - & - & - & - & - & - & - & 2.8 & 0.1 & 1.6 & - & 1.6 \\
\hline 21 & linalool acetate & 1251.8 & 15.0 & 1.7 & - & - & - & - & - & - & - & - & 16.7 & 0.8 & 7.8 & - & 7.8 \\
\hline 22 & lavandulyl acetate & 1286.4 & 2.9 & - & - & - & - & - & - & - & - & - & 2.9 & 0.1 & 1.9 & - & 1.9 \\
\hline 23 & limonen-10-ol & 1288.4 & 1.4 & - & - & - & - & - & - & - & - & - & 1.4 & 0.1 & - & - & - \\
\hline \multirow[t]{8}{*}{24} & hexadecane $(\mathrm{C} 16)^{\mathrm{C}}$ & 1575.3 & & & & & & & & & & & & & & & \\
\hline & SUM of identified compounds & & 1281.6 & 423.3 & 212.4 & 106.7 & 63.9 & 30.9 & 22.1 & 15.4 & 10.1 & 7.8 & 2174.2 & & 2141.3 & 110.1 & 2251.4 \\
\hline & Recovery ratio $[\%]$ & & 58.9 & 19.5 & 9.8 & 4.9 & 2.9 & 1.4 & 1.0 & 0.7 & 0.5 & 0.4 & & & 95.11 & 4.89 & \\
\hline & Cumulative recovery [\%] & & 58.9 & 78.4 & 88.2 & 93.1 & 96.0 & 97.5 & 98.5 & 99.2 & 99.6 & 100.0 & & & & & \\
\hline & Monoterpenes & & & & & & & & & & & & 0.0 & & & & 0.0 \\
\hline & Oxigenated monoterpenes & & & & & & & & & & & & 2174.2 & & & & 2251.4 \\
\hline & Sesquiterpenes & & & & & & & & & & & & 0.0 & & & & 0.0 \\
\hline & Oxigenated sesquiterpenes & & & & & & & & & & & & 0.0 & & & & 0.0 \\
\hline \multicolumn{18}{|c|}{$\begin{array}{l}\text { an.i. - stands for not identified compounds } \\
\text { bRI - retention index relative to } C_{8}-C_{40} n \text {-alkanes on InertCap5 column } \\
\text { cInternal standard }\end{array}$} \\
\hline
\end{tabular}



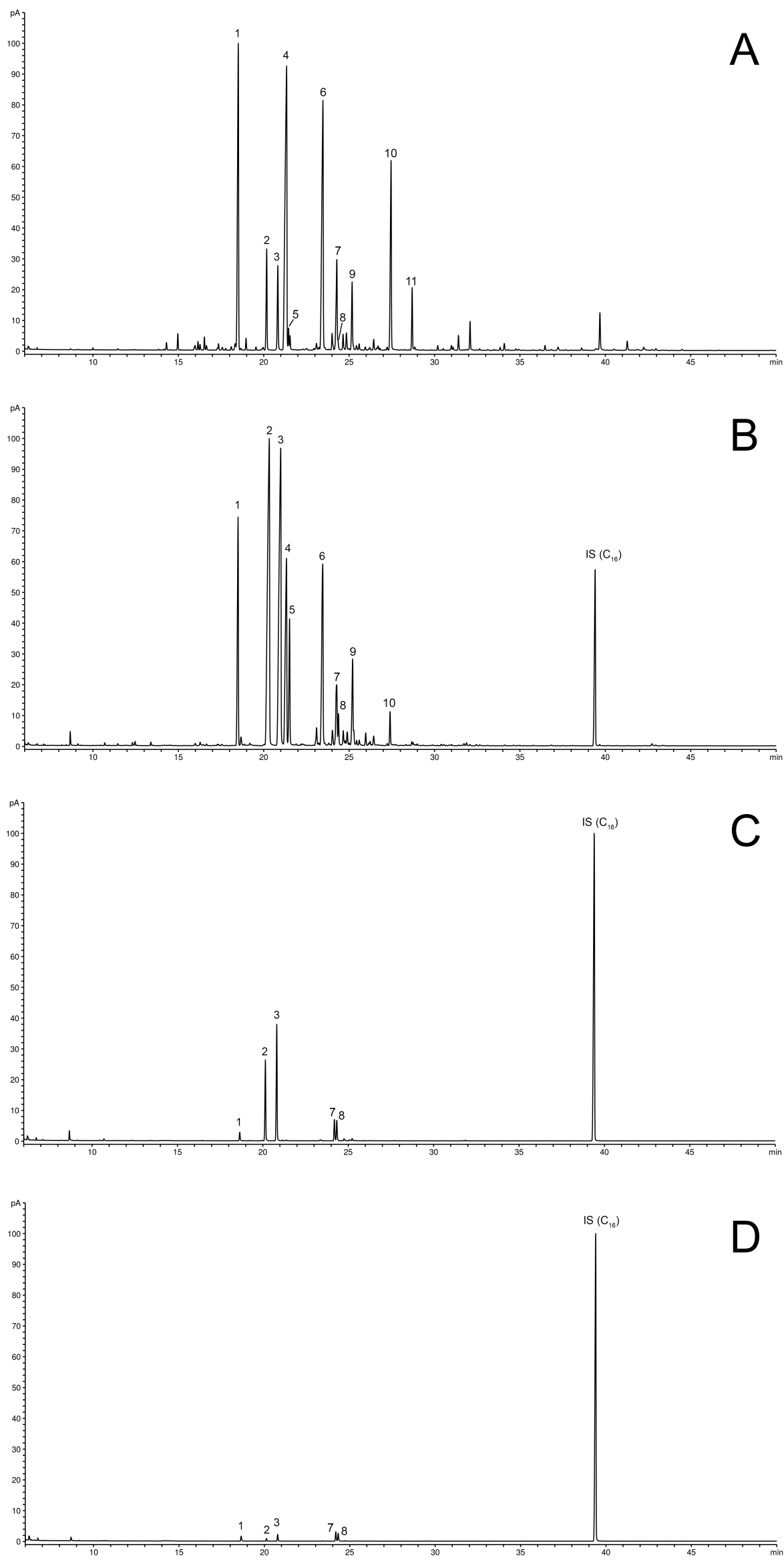

Fig. 2. GC-chromatograms of lavandin (Lavandula $\times$ intermedia) A - essential oil; B - hydrolat $1^{\text {st }}$ extraction; C - hydrolat $5^{\text {th }}$ extraction; D hydrolat $10^{\text {th }}$ extraction; 1 - 1,8-cineole; 2 - cis-furanoid linalool oxide; 3 - trans-furanoid linalool oxide; 4 - linalool; 5 - hotrienol; 6 - camphor; 7 - cis-pyranoid linalool oxide + borneol; 8 - trans-pyranoid linalool oxide; 9 - $\alpha$-terpineol; 10 - linalool acetate; 11 - lavandulyl acetate; IS(C16) internal standard (hexadecane). 
The first extraction with $n$-hexane had the highest yield of all dissolved compounds, while each subsequent extraction had a decreasing amount. The recovery of the compounds from the hydrolat did not proceed uniformly during the extractions. The number of extracted compounds decreased from the first to the fourth extraction, after which traces of five compounds were retained until the last extraction. Those compounds were 1,8-cineole, cis- and trans-furanoid linalool oxides, and cisand trans-pyranoid linalool oxides. It may be important to note here that borneol did not co-eluted with cis-pyranoid linalool oxide after the third extraction. Figure 1 shows the $n$-hexane recovery of the eight most dominant compounds from lavandin hydrolat. Hereby, the recovery ratio of total compounds yield after the third, fifth, and eighth extractions is presented here $(88 \%, 96 \%$, and $99 \%$, respectively). Śmigielski et al. (2013) also reported higher volatile compounds recovery with an increased number of extraction cycles. They also reported that, extraction of $97 \%$ of the volatile compounds from the hydrolat was achieved with five LLE cycles.

In Figure 2, chromatograms of essential oil and chosen hydrolat extraction cycles $\left(1^{\text {st }}, 5^{\text {th }}\right.$, and $\left.10^{\text {th }}\right)$ have been shown. This presentation provides insight into the similarity of the chemical composition of essential oil and hydrolat, as well as the gradual depletion of compounds from aqueous solution in higher extraction cycles. The main weakness of this method is that even after ten consecutive $n$-hexane extractions of volatile compounds from the hydrolat, not all components are depleted to level below the detection on the gas chromatogram. Therefore, other non-polar solvents should be explored in further research. Furthermore, the choice of aliphatic internal standard could be further considered since hexadecane (C16) in our GC method elutes at a time very close to eluation time of trans-caryophyllene (RT $\sim 40 \mathrm{~min}$, Figure $2 \mathrm{~A}$ ). This did not interfere with the hydrolat analysis, as only oxigenated monoterpene compounds dissolved in the hydrolat and no traces of sesquiterpenes were detected, but it would be desirable to design an internal standard elution at the time where other components do not elute nearby.

\subsection{Combined fractions}

In order to verify the obtained results of quantification of volatile compounds in individual extraction cycles, we quantified the extractions combined into two groups of 1-5 cycles and 6-10 cycles (Table 2). The chemical composition of the combined extractions differed slightly from that of the individual fractions study. The most important difference is that the entire amount of 1,8-cineole was extracted in the first five cycles, while the lavander lactone was abundant in the second five cycles. This discrepancy may be due to sampling, as a new distillation was performed for grouped fractions yield validation purposes. However, the total yield of extracted volatile compounds from the hydrolat almost coincides with the total yield of components from the ten cycles of the dynamic study ( $2174.2 \mathrm{mg} / \mathrm{L}$ and $2251.4 \mathrm{mg} / \mathrm{L}$ ). Judging by the cumulative recovery, it can be concluded that in the first 5 cycles more than $95 \%$ of the total yield (from 10 cycles) of extracted volatile compounds has been collected.

\section{CONCLUSION}

The chemical composition of the lavandin hydrolat showed high similarity with its essential oil. However, analysis revealed that the volatile compounds dissolved in water exclusively belonged to the class of oxygenated monoterpenes. In ten consecutive liquid-liquid extractions of lavandin hydrolat total amount of $2174.2 \mathrm{mg} / \mathrm{L}$ extracted compounds has been quantified. The most dominant compounds in lavandin hydrolat were cis- and trans-furanoid linalool oxide (676.3 and $634.1 \mathrm{mg} / \mathrm{L}$, respectively), followed by much smaller amounts of linalool, camphor, and 1,8-cineole (167.6, 157.0, and 148.2 $\mathrm{mg} / \mathrm{L}$, respectively). The number of extracted compounds decreased from the first to the fourth extraction, after which traces 1,8-cineole, cis- and trans-furanoid linalool oxides, and cis- and trans-pyranoid linalool oxides were retained until the last extraction. Cumulative recoveries of total compounds yield after the third, fifth, and eighth extractions were $88 \%$, $96 \%$, and $99 \%$, respectively. Method verification confirmed that in the first 5 cycles more than $95 \%$ of the total yield (from 10 cycles) of extracted volatile compounds can be collected. Therefore, based on the results of this study, for the purpose of volatile compounds quantification in lavandin hydrolat $5 \mathrm{cy}-$ cles of $n$-hexane liquid-liquid extraction can be recommended.

\section{ACKNOWLEDGMENTS}

This work was supported by the Ministry of Education, Science and Technological Development of the Republic of Serbia (Contract No. 451-03-68/2020-14/ 200003).

\section{REFERENCES}

Adams, R. P. (2007). Identification of essential oil components by Gas Chromatography/Mass Spectorscopy, Allured Publishing Corporation.

Arabaci, O., Bayram, E., Baydar, H., Savran, A. F., Karadogan, T. and Ozay, N. (2007). Chemical composition, yield and contents of essential oil of Lavandula hybrida Reverchon grown under different nitrogen fertilizer, plant density and location, Asian Journal of Chemistry 19(3): 2184-2192.

Bajalan, I., Rouzbahani, R., Pirbalouti, A. G. and Maggi, F. (2017). Chemical composition and antibacterial activity of Iranian Lavandula $x$ hybrida, Chemistry $\mathcal{E}$ Biodiversity 14(7): e1700064.

Baydar, H. and Kineci, S. (2009). Scent composition of essential oil, concrete, absolute and hydrosol from lavandin (Lavandula $x$ intermedia Emeric ex Loisel.), Journal of Essential Oil Bearing Plants 12(2): 131-136.

Blažeković, B., Yang, W., Wang, Y., Li, C., Kindl, M., Pepeljnjak, S. and Vladimir-Knežević, S. (2018). Chemical composition, antimicrobial and antioxidant activities od essential oils of Lavandula $x$ intermedia 'Budrovka' and L. angustifolia cultivated in Croatia, Industrial Crops and Products 123: 173-182.

Carrasco, A., Martinez-Gutierrez, R., Tomas, V. and Tudela, J. (2016). Lavandin (Lavandula $x$ intermedia Emeric ex Loiseleur) essential oil from Spain: determination of aromatic profile by gas chromatography-mass spectrometry, antioxidant and lipoxygenase inhibitory bioactivities, Natural Product Research 30(10): 1123-1130.

Catty, S. (2001). Hydrosols: The next aromatherapy, original ed. edition edn, Healing Arts Press, Rochester, Vt.

Chen, H., Davidson, P. M. and Zhong, Q. (2014). Impacts of sample preparation methods on solubility and antilisterial characteristics of essential oil components in milk, Applied and Environmental Microbiology 80(3): 907-916.

Garzoli, S., Petralito, S., Ovidi, E., Turchetti, G., Masci, V. L., Tiezzi, A. and et al. (2020). Lavandula $x$ intermedia essential oil and hydrolate: Evaluation of chemical composition and antibacterial activity before and after formulation in nanoemulsion, Industrial Crops and Products 145: 112068.

Jeon, D. H., Moon, J. Y., Hyun, H. B. and Cho, S. K. (2013). Composition analysis and antioxidant activities of the essential oil and the hydrosol extracted from Rosmarinus officinalis 
L. and Lavandula angustifolia Mill. produced in Jeju, Journal of Applied Biological Chemistry 56(3): 141-146.

Kaloustian, J., Mikail, C., Abou, L., Vergnes, M.-F., Nicolay, A. and Portugal, H. (2008). Nouvelles perspectives industrielles pour les hydrolats, Acta Botanica Gallica 155(3): 367373. [in France].

Kara, N. and Baydar, H. (2013). Determination of lavender and lavandin cultivars (Lavandula sp.) containing high quality essential oil in Isparta, Turkey, Turkish Journal of Field Crops 18(1): 58-65.

Kunicka-Styczyńska, A., Śmigielski, K., Prusinowska, R., Rajkowska, K., Kuśmider, B. and Sikora, M. (2015). Preservative activity of lavender hydrosols in moisturizing body gels, Letters in Applied Microbiology 60(1): 27-32.

Labadie, C., Ginies, C., Guinebretiere, M.-H., Renard, C. M., Cerutti, C. and Carlin, F. (2015). Hydrosols of orange blossom (Citrus aurantium), and rose flower (Rosa damascena and Rosa centifolia) support the growth of a heterogeneous spoilage microbiota, Food Research International 76: 576-586.

Lesage-Meessen, L., Bou, M., Sigoillot, J.-C., Faulds, C. B. and Lomascolo, A. (2015). Essential oils and distilled straws of lavender and lavandin: a review of current use and potential application in white biotechnology, Applied Microbiology and Biotechnology 99(8): 3375-3385.

Lis-Balchin, M. (ed.) (2002). Lavender: the genus Lavandula, number v. 29 in Medicinal and aromatic plants-industrial profiles, Taylor \& Francis, London ; New York.

Martínez-Gil, A., Pardo-García, A., Zalacain, A., Alonso, G. and Salinas, M. (2013). Lavandin hydrolat applications to Petit Verdot vineyards and their impact on their wine aroma compounds, Food Research International 53: 391-402.

Śmigielski, K. B., Prusinowska, R., Krosowiak, K. and Sikora, M. (2013). Comparison of qualitative and quantitative chemical composition of hydrolate and essential oils of lavender (Lavandula angustifolia), Journal of Essential Oil Research 25(4): 291-299.

Ph. Jug. IV (1984). Pharmacopoea Jugoslavica, $4^{\text {th }}$ edn, Federal Institute of Public Health, Belgrade, Yugoslavia.

Pistelli, L., Najar, B., Giovanelli, S., Lorenzini, L., Tavarini, S. and Angelini, L. (2017). Agronomic and phytochemical evaluation of lavandin and lavender cultivars cultivated in the Tyrrhenian area of Tuscany (Italy), Industrial Crops and Products 109: 37-44

Politi, M., Menghini, L., Conti, B., Bedini, S., Farina, P., Cioni, P. L., Braca, A. and De Leo, M. (2020). Reconsidering hydrosols as main products, Molecules 25(9).

Price, L. and Price, S. (eds) (2004). Understanding hydrolats: The specific hydrosols for aromatherapy: A guide for health professionals, $1^{\text {st }}$ edn, Churchill Livingstone, Edinburgh; New York.

Prusinowska, R., Śmigielski, K., Stobiecka, A. and KunickaStyczyńska, A. (2016). Hydrolates from lavender (Lavandula angustifolia) - their chemical composition as well as aromatic, antimicrobial and antioxidant properties, Natural Product Research 30(4): 386-393.

Rajeswara Rao, B. (2013). Hydrosols and water-soluble essential oils: their medicinal and biological properties., in J. Govil and S. Bhattacharya (eds), Recent Progress in Medicinal Plants: Essential Oils I, $1^{\text {st }}$ edn, Vol. 36, Studium Press LLC, Houston, chapter $1^{\text {st }}$, pp. 119-140.
Renaud, E. N. C., Charles, D. J. and Simon, J. E. (2001). Essential oil quantity and composition from 10 cultivars of organically grown lavender and lavandin, Journal of Essential Oil Research 13(4): 269-273.

Rose, J. (1999). 375 essential oils and hydrosols, Illustrated edn, North Atlantic Books, Berkeley, Calif.

Tannous, P., Julini, R., Wang, M. and Simon, M. (2004). Water balance in hydrosol production viasteam distillation: case study using lavandin (Lavandula $x$ intermadia), New Use Agriculture andnatural Plant Products and ASNAPP Program, New Jersey, USA.

Tucker, A., Maciarello, M. and Howell, J. (1984). A preliminary analysis of some lavender and lavandin cultivars, Perfumer and flavorist 9: 49-52.

Yalkowsky, S. H., He, Y., Jain, P., He, Y. and Jain, P. (2016) Handbook of aqueous solubility data, CRC Press.

Yohalem, D. and Passey, T. (2011). Amendment of soils with fresh and post-extraction lavender (Lavandula angustifolia) and lavandin (Lavandula $x$ intermedia) reduce inoculum of Verticillium dahliae and inhibit wilt in strawberry, Applied Soil Ecology 49: 187-196. 